\title{
La conceptualización de la Historia escolar y sus implicaciones didácticas. Un estudio a partir del recuerdo de estudiantes de BUP*
}

\author{
David Parra Monserrat \\ Departament de Didàctica de les Ciències Experimentals i Socials \\ Universitat de València
}

Resumen: Este trabajo, basado en la memoria escolar y los recuerdos recogidos a partir de cuarenta entrevistas semiestructuradas, indaga en los contenidos, los enfoques, las finalidades y las representaciones de unas clases de Historia cursadas por alumnos y alumnas de la provincia de Castellón que estudiaron Historia de España en los últimos años de vigencia del Bachillerato Unificado Polivalente (BUP). El estudio permite detectar la vigencia de una concepción de la Historia que lleva a naturalizar determinadas construcciones histórico-culturales, a rechazar la presencia de la política en las aulas o a defender una idea de objetividad que, sin duda, lastra o impide el desarrollo de una Historia crítica y socialmente útil.

Palabras clave: Didáctica de la Historia, memoria, conceptualización, identidad, finalidades educativas.

Abstract: This paper, based on forty semi-structured interviews focused on school memories, delves into the contents, approaches, purposes and representations of some History classes taken by students of the province of Castellón who studied Spanish History in the last years of the Polyvalent Unified Baccalaureate (BUP). The study reveals the existence of a conception of History which leads to naturalize certain historical and cultural constructions, to reject the presence of politics in the classroom or to defend an idea of objectivity which complicated or prevented the development of a critical and socially useful History.

Keywords: History education, memory, conceptualization, identity, educational objectives.

(Fecha de recepción: junio, 2013, y de aceptación: septiembre, 2013)

DOI: 10.7203/DCES.27.2653

\footnotetext{
* El texto se enmarca en el proyecto de investigación «De la dictadura nacionalista a la democracia de las autonomías: política, cultura, identidades colectivas» (HAR 2011-27392), financiado por el Ministerio de Economía y Competitividad. El autor, además, colabora con el proyecto «La formación de los jóvenes en Historia de España y su relevancia en el desarrollo de las competencias ciudadanas. Estudio de resultados al concluir el Bachillerato y las PAU» (EDU2010-16286), financiado por el Ministerio de Educación y Ciencia. El autor agradece a los profesores Josep Ramon Segarra, Xosé Manuel Souto y Rafael Valls sus comentarios y sugerencias.
} 
"No hay ni ha habido jamás una práctica educativa [...] comprometida únicamente con ideas preponderantemente abstractas e intocables. Insistir en eso y tratar de convencer a los incautos de que ésa es la verdad es una práctica política indiscutible con que se intenta suavizar una posible rebeldía de las víctimas de la injusticia."

\section{Paulo Freire, Pedagogía de la} esperanza

\section{Introducción}

Decía Leopold von Ranke que la función del historiador es "exponer cómo sucedieron realmente las cosas". Ranke, considerado el representante más significativo del historicismo clásico decimonónico, defendía una concepción científica de la Historia que pasaba por rechazar todo juicio de valor y especulación metafísica y por recurrir a un método críticoheurístico que permitiese "la rigurosa exposición del hecho", lo que garantizaba, según él, la "objetividad" del relato histórico y su cientificidad (Iggers, 1998, p. 27). Aunque el modelo "imparcial" de los historicistas no estaba desprovisto de fuertes contradicciones epistemológicas, su forma de aproximarse y de "comprender" el pasado tuvo un gran éxito en la Europa del siglo XIX, de ahí que, en un intento de hacerlo suyo, determinadas interpretaciones posteriores simplificaran el método rankeano y lo degradaran a un positivismo del hecho histórico que llevaba a identificar la "objetividad" con una simple narración factual (Carreras, 2000).

El historicismo del siglo XIX y las lecturas posteriores que se hicieron del mismo (por no hablar del positivismo y sus fundamentos epistemológicos) pusieron las bases para una nueva concepción de la Historia que, con más o menos modificaciones, ha llegado hasta nuestros días; una historia obsesionada por los hechos y los documentos y centrada en la búsqueda de una "verdad" imparcial que permitiera acceder a un pasado en absoluto concebido, utilizando la expresión de Lowenthal (1998), como "un lugar extraño".

Aunque, como señala Raimundo Cuesta (1997), la constitución de la Historia como saber escolar no fue consecuencia de la institucionalización de la comunidad científica de historiadores, consideramos que estas concepciones de la historiografía académica no estuvieron completamente al margen de la configuración del código disciplinar de la Historia escolar (aunque pudieran diferir en sus finalidades socioeducativas y políticas) ni de las representaciones más o menos simples, más o menos populares, que, de la misma, se han ido conformando con el paso del tiempo. No lo estuvieron en el siglo XIX, cuando el historicismo y el positivismo eran las grandes tendencias hegemónicas en el campo de la historiografía; pero tampoco en la actualidad, pese a tener que convivir con otros enfoques epistemológicos preconizadores de un tipo de Historia y 
de unos usos públicos completamente distintos.

Teniendo todo esto presente, este artículo pretende analizar hasta qué punto una determinada concepción de la Historia puede influir en el desarrollo de una didáctica crítica y en qué medida la reivindicación de una Historia "neutra" y despolitizada, a menudo asociada con la simple descripción o narración de hechos, esconde una legitimación de los discursos hegemónicos, coartando el potencial transformador de la enseñanza de la Historia.

Para reflexionar acerca de todas estas cuestiones, tal y como expresa el subtítulo de este texto, no partiremos directamente del currículum oficial ni del real, sino del currículum retenido, es decir, de las representaciones y recuerdos de personas que estudiaron Bachillerato durante la década de los noventa y que dan cuenta de prácticas, conceptos, interpretaciones y valores influenciados por la experiencia escolar, pero también por un contexto sociocultural más amplio. La investigación, así, permite averiguar qué queda de una disciplina escolar más de una década después de haberla estudiado y comprobar hasta qué punto esos recuerdos, siempre selectivos y condicionados por aspectos externos como el ambiente familiar, la formación posterior o la influencia de los medios, han dado lugar a una memoria social de la Historia escolar a menudo descuidada por los estudios centrados en la construcción de las memorias colectivas (Carretero, Rosa y González, 2006).

\section{Metodologíautilizada,descripción de la muestra y finalidades perseguidas}

Para favorecer una transformación en el ámbito de cualquier disciplina escolar, tan importante como intentar cambiar los modelos de enseñanza-aprendizaje y las rutinas diarias del aula es comprender los mecanismos ideológicos y culturales que han conducido a determinadas representaciones que impiden avanzar en la construcción de una escuela más innovadora, más cívica y más crítica (Lomas, 2011; Cuesta, 1997).

Con la intención de aproximarnos a estas representaciones, hemos llevado a cabo una investigación que, centrada en la enseñanza de la Historia de España, pretende detectar cambios y continuidades por lo que respecta a enfoques, rutinas, prácticas y finalidades socioeducativas ${ }^{1}$. Para ello, hemos partido del recuerdo de 40 personas ( 21 mujeres y 19 hombres) que estudiaron tercero de BUP (curso académico en el que se estudiaba Historia de España) en la provincia de Castellón durante la década de los noventa del siglo XX y que respondían a características diversas en relación con la edad, el lugar de procedencia, los estudios posteriores o la dedicación profesional (Gráficas I a V).

\footnotetext{
${ }^{1}$ Esta investigación ha dado lugar a un Trabajo de Fin de Máster titulado Història, identitats i memòria escolar. Canvis i continü̈tats en l'ensenyament de la Història a Castelló, dirigido por el Dr. Xosé Manuel Souto y defendido en la Facultat de Magisteri de la Universitat de València en 2012.
} 


\section{GrÁFICA I}

\section{Datos básicos de la muestra: edad de los participantes}

en el momento de la entrevista

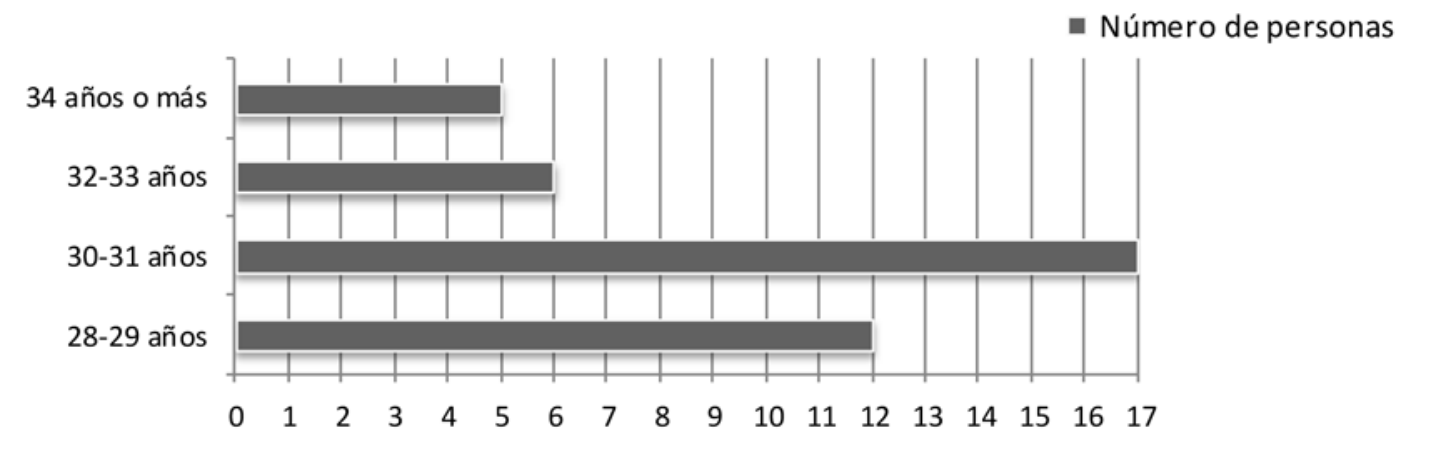

\section{GRÁFICA II}

Datos básicos de la muestra: curso académico en el que estudiaron Geografía e Historia de España de $3^{\circ}$ de BUP

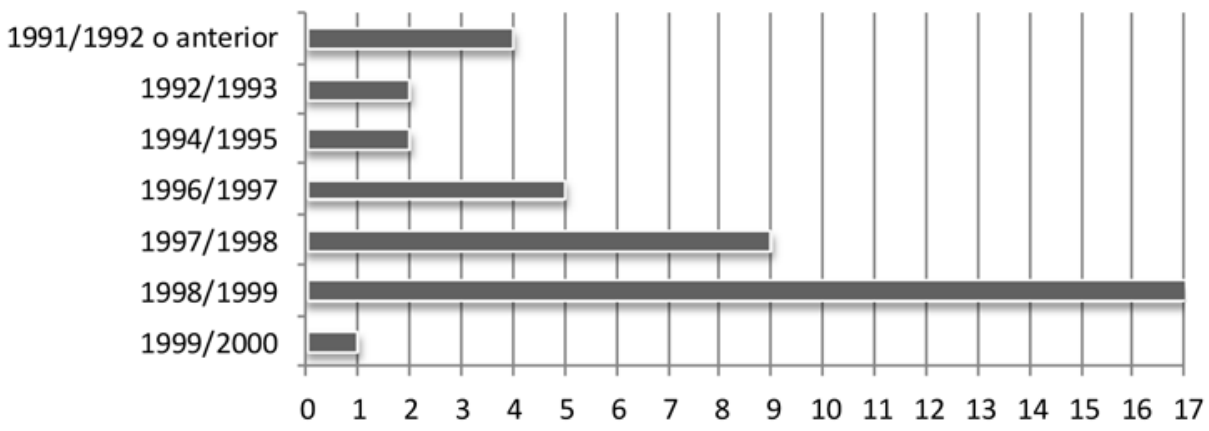

\section{GrÁFICA III}

Datos básicos de la muestra:

Instituto de procedencia

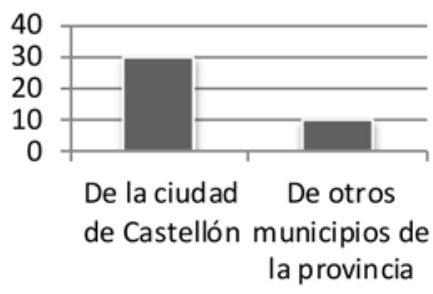

Para indagar en el recuerdo, recurrimos a la entrevista semiestructurada, ya que el proceso de rememoración a menudo exige una contextualización y unos estímulos difíciles de contemplar con otro tipo de técnicas. Las entrevistas, individuales y con una duración aproximada de 45 minutos, se basaban en un cuestionario abierto compuesto por diez preguntas de diferente natu- 

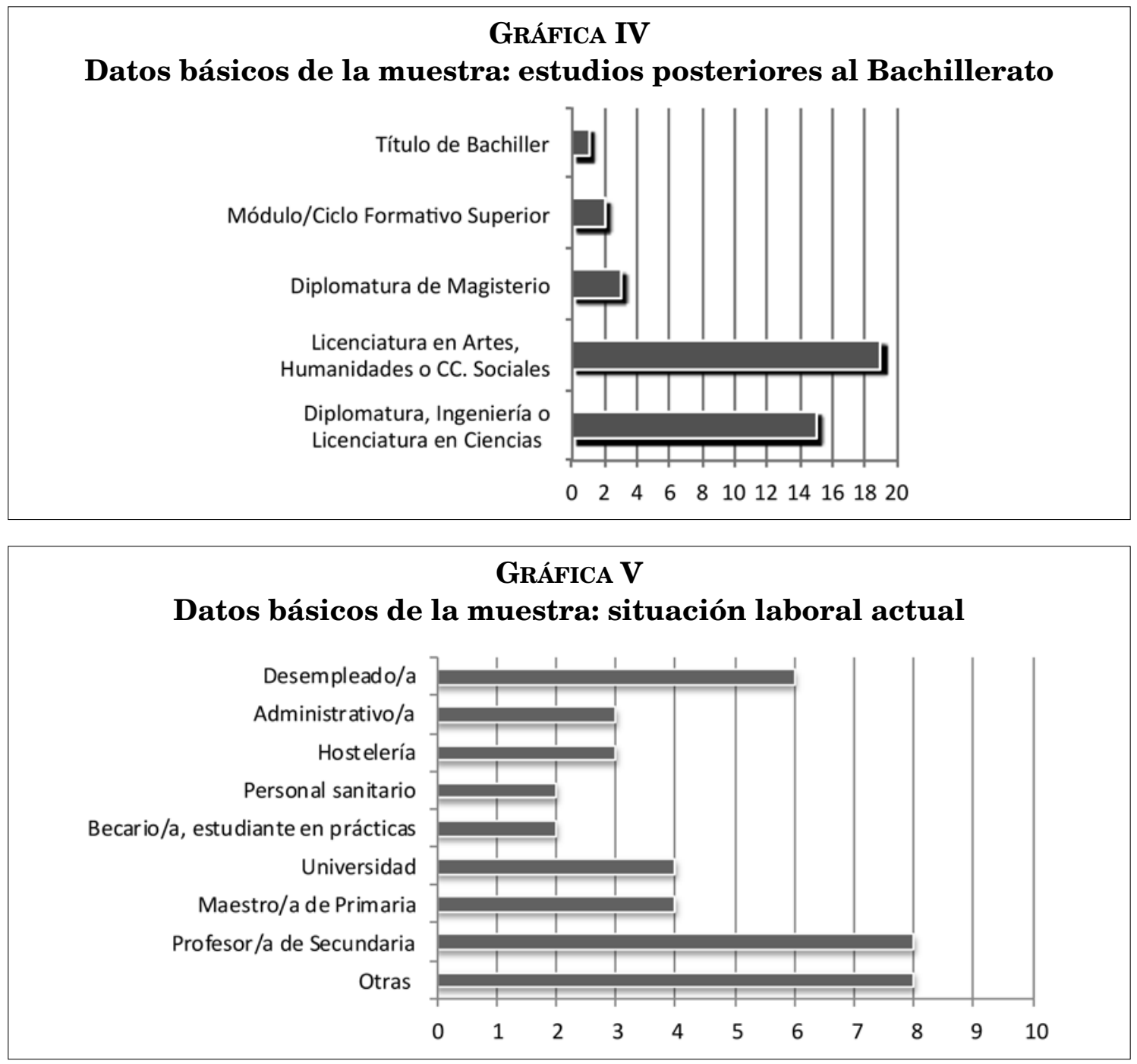

raleza además de un test de asociación de palabras que contribuía a perfilar el significado de algunas de las respuestas previas $^{2}$. Tras unos minutos iniciales en los que se preguntaba acerca de cuestiones o valoraciones de carácter general (sensaciones que producía la asignatu- ra, información sobre el transcurso diario de la clase, sobre la actitud y personalidad del profesor o profesora, etc.), las primeras preguntas iban destinadas a "reconstruir" aquellas clases de Historia (Cuadro I) para, posteriormente, poder examinar las opiniones y concep-

${ }^{2}$ El test de asociación incluía conceptos tan variados como revolución, nación, democracia, ciudadanía, origen o reconquista. Las respuestas de los participantes, pese a ser libres, siempre debían tener como referencia la Historia de España. 
ciones que, en parte, sustentaban esos recuerdos (Cuadro II). La realización de las entrevistas, así, no sólo buscaba la obtención de información para acercarse a la Historia enseñada/aprendida en los últimos años de vida del Bachillerato Unificado Polivalente, sino también la aproximación a toda una serie de factores y elementos afectivos claves a la hora de configurar las representaciones o memorias de una disciplina escolar y, por tanto, enormemente significativos para una investigación de estas características.

El análisis de los recuerdos de los exalumnos en relación con los procesos de enseñanza-aprendizaje, por tanto, nos ha permitido penetrar en las interiori-

\section{Cuadro I \\ Tipos de preguntas para "reconstruir" las clases de Historia}

\section{Sobre contenidos trabajados}

2. En relación con lo que recuerda de la Historia de España de $3^{\circ}$ de BUP, ¿podría poner 10 ejemplos que fueran relevantes para el profesor o para la asignatura de...

a) Acontecimientos históricos:

b) Personajes históricos:

c) Procesos explicativos trabajados:

d) Problemáticas sociales trabajadas (en este caso, indique por favor si se establecían conexiones con problemas del presente):

\section{Sobre evaluación}

5. ¿Cómo era la evaluación? (Especifique, por favor, si había trabajos, si había exámenes, cada cuánto tiempo se realizaban, si respondían a alguna lógica temática, qué tipo de preguntas se hacía, etc.)

\section{CuAdro II}

\section{Tipos de preguntas sobre opiniones y concepciones}

\section{Sobre finalidades}

6. ¿Cuáles cree que eran los objetivos o finalidades de esta asignatura? ¿Cree que tenía alguna finalidad social más allá del aprendizaje de contenidos históricos?

\section{Sobre la neutralidad en la clase de Historia}

7. ¿Cree que las clases de Historia de España estaban ideologizadas o que el profesor las utilizaba con fines políticos? ¿Por qué? En su opinión, ¿es correcto que el profesor de Historia se posicione de alguna manera? ¿En algunos casos sí y en otros no? ¿Por qué? 
dades del sistema educativo para ver no sólo algunos de los contenidos, enfoques o rutinas que presidían las clases, sino también las conexiones entre aquello que guardamos en nuestra memoria y los valores y subjetividades que, desde entonces, nos han hecho como somos. No podemos olvidar, además, que los recuerdos siempre son un modo de conciencia retrospectiva, por lo que debemos tener muy presente que en su configuración han influido tanto las imágenes de lo que "realmente pasó", como las simpatías y antipatías, los valores sociales dominantes o el momento actual del proceso de construcción de la propia identidad (Escolano, 2011; Cuesta, 1997).

Atendiendo a todas estas cuestiones, el artículo se estructura en dos partes claramente diferenciadas. En la primera damos cuenta de esa "reconstrucción" de las clases de Historia de España de finales del siglo XX a partir del recuerdo de las personas entrevistadas. En la segunda, profundizamos en el grado de análisis, centrándonos en el informante y en su opinión acerca de la concepción de la Historia; una concepción en cuya configuración ha influido el recuerdo de la experiencia escolar, pero también toda una serie de factores externos que, como las teleseries o películas de contenido histórico, las discusiones públicas sobre los usos del pasado o determinados debates mediáticos como el de la memoria histórica, han contribuido sin duda a remodelar ese recuerdo y, por tanto, a dotar de contenido determinadas representaciones de la Historia escolar pro- fundamente extendidas e incluso "naturalizadas".

\section{Las clases de Historia de España en el recuerdo del alumnado de $\boldsymbol{B U P}$}

\section{Metodología docente y contenidos}

El estudio de las 40 entrevistas realizadas aporta, en primer lugar, una valiosa información sobre la relación personal de los entrevistados con la asignatura de Historia. Frente a la pregunta "cuál es tu recuerdo global y la valoración de la asignatura de Historia de España de tercero de BUP”, aproximadamente la mitad de las personas entrevistadas (18 de 40) presentaba una imagen positiva de la misma vinculada a adjetivos como "interesante", "amena" o "participativa”. La otra mitad (22 de 40), en cambio, hablaba de un recuerdo negativo relacionado con palabras como "memorización", "pasividad", "aburrimiento", "rutina" o "tradicional".

Como ya han señalado diversas investigaciones (Martínez, Souto, y Beltrán, 2006; Fuentes, 2004), todo indica que, tanto en unos casos como en otros, la implicación, la actitud y la conducta de los profesores desempeñaron un papel crucial en la representación y el recuerdo de la Historia escolar de estos alumnos, ya que era algo de lo que daban cuenta la práctica totalidad de los entrevistados:

E4: "Jo crec que era una de les millors professores: sempre ajudant-te, sempre pendent de cada 
alumne, tant dels que més sabien com dels que més els costava la història" ["Yo creo que era una de las mejores profesoras: siempre ayudándote, siempre pendiente de cada alumno, tanto de los que más sabían como de aquellos a los que más les costaba la historia"].

E24: "L'actitud cap als estudiants era prou distanciada, hi havia una barrera entre professora $i$ alumnat" ["La actitud hacia los estudiantes era bastante distanciada, había una barrera entre profesora y alumnado"].

E26: "Era un señor tradicional y muy serio".

E34: "La profesora era una motivadora incansable, ponía toda su dedicación para hacer la clase más interesante".

De la actuación docente, el uso de una determinada metodología era uno de los aspectos que más influía en la valoración del profesorado y del conjunto de la clase de Historia. En este sentido, la clase magistral basada en la toma de apuntes (concebida como la reproducción del saber académico) era, con diferencia ${ }^{3}$, el principal eje vertebrador de las sesiones, lo cual implicaba, para la mayoría del alumnado, un recuerdo negativo de la asignatura:
E5: "Recuerdo bien al profesor y recuerdo que no me gustaba especialmente [...] se ponía a explicarnos la lección por temas de memoria, no utilizaba ningún tipo de apuntes ni nada. No interactuaba demasiado con nosotros. Yo a veces me aburría y me quedaba mirando las fotos del libro. Mi sensación general era un poco de aburrimiento, y eso que a mí la historia me llamaba la atención. Pero no me gustaba el profesor, ni cómo lo trataba".

E24: "Ella entrava, soltava la xapa, agafàvem apunts i ja està; no fèiem activitats" ["Ella entraba, soltaba la chapa, cogíamos apuntes y ya está; no hacíamos actividades"].

E33: "Del profesor no aprendí nada ya que se dedicaba la mayor parte de la clase a contar sus batallitas y curiosidades de Castellón en sus años mozos y le dedicaba a la asignatura como tal la mitad del tiempo de clase. Después, antes del examen, se cogía el libro y a estudiar".

Más allá de la metodología, del modelo de enseñanza y de los elementos afectivos, los contenidos tratados también influían en el recuerdo de las clases. Del análisis de las entrevistas se desprende que aquello que mayoritariamente

\footnotetext{
${ }^{3}$ Preguntados sobre la metodología docente, el ítem dedicado a la "clase magistral basada en la toma de apuntes" obtuvo una puntuación de 3,45 en una escala de 1 a 4 (siendo 1: nunca y 4: prácticamente siempre/siempre).
} 
recordaban los antiguos alumnos castellonenses de BUP eran hechos (189 respuestas correspondientes a 49 hechos distintos) y personajes (274 respuestas correspondientes a 60 personajes diferentes). Muy pocos, en cambio, hablaban de procesos históricos (84 respuestas correspondientes a 22 procesos) o del uso de la historia para analizar problemáticas sociales y conectarlas con el presente (44 respuestas correspondientes a 22 problemáticas).

La mayoría de los acontecimientos históricos recordados tenía un carácter bélico $(52,7 \%)$ y/o político. En cambio, pocos hacían referencia a cuestiones sociales o económicas. Buena parte de estos acontecimientos, además, eran los mismos que habían dado cuerpo a las programaciones y manuales del siglo XIX (la "Reconquista", la "unión" de Castilla y Aragón bajo los Reyes Católicos, el "descubrimiento" y conquista de América, la Guerra de la Independencia, la promulgación de la Constitución de Cádiz, etc.); unos acontecimientos que, históricamente, habían servido para articular un relato nacionalizador que, con unos orígenes remotos, buscaba las raíces españolas en épocas muy lejanas (Valls, 1991; Maestro, 2005; Parra, 2012). En este sentido, debemos conectar esta información con una pregunta posterior en la que se pedía a los entrevistados que dijeran en qué momento empezaba la asignatura y cuándo acababa, ya que sus respuestas venían a confirmar la existencia de un discurso teleológico (y en algunos casos esencialista) que, iniciado en la Anti- güedad o, incluso, en la Prehistoria, era visto por los antiguos alumnos de BUP como "natural".

Si nos centramos en los personajes, percibimos enseguida el gran peso de los reyes en el recuerdo de la historia escolar (176 de 274 referencias a personajes eran monarcas). Resulta significativa la gran ausencia de mujeres (sólo el 6,6\% de las referencias) o el hecho de que todas las que aparecían (con la excepción de Victoria Kent) fuesen reinas. Esto confirma, una vez más, el enfoque androcéntrico del relato histórico denunciado por numerosos trabajos a lo largo de las últimas décadas (Moreno, 1986; Morant, 1996; Scott, 2008).

Las dinastías y los reyes, como afirmaban muchas de las personas entrevistadas, solían ser, además, un eje de articulación temporal, por lo que era habitual la organización de la asignatura atendiendo a reinados más que a épocas, etapas políticas o procesos socioeconómicos. En relación con esta última cuestión, ya hemos indicado que los procesos históricos tenían un peso sensiblemente menor, lo que se desprende tanto de los recuerdos como de afirmaciones como las siguientes:

E13: "Jo no recorde que treballàrem processos. Era molt més factual, processos com a tal, no" ["Yo no recuerdo que trabajáramos procesos. Era mucho más factual, procesos como tal, no"].

E24: "Ella feia una història molt més de fets, no hi havia explicacions ni de causes ni de conseqüències, ni de 
totes estes coses. No em sona gens. De fet, sé que és així perquè contrasta molt amb una altra manera d'estudiar història que tinguérem l'any següent $i$ que haviem tingut en anys anteriors $i$ que era molt més de processos" ["Ella hacía una historia mucho más de hechos, no había explicaciones ni de causas ni de consecuencias, ni de todas estas cosas. No me suena nada. De hecho, sé que es así porque contrasta mucho con otra manera de estudiar historia que tuvimos el año siguiente y que habíamos tenido en años anteriores y que era mucho más de procesos"].

Igualmente, las referencias a una historia viva, relacionada con problemas coetáneos, eran escasas. Aproximadamente la mitad de los entrevistados decía que "no es plantejaven problemes socials per fer significativa la història" ["no se planteaban problemas sociales para hacer significativa la historia"] (E13) o que "era una història desconnectada del present" ["era una historia desconectada del presente"] (E32). Incluso algunos de los que reconocían haber trabajado problemas sociales, como la condición de la clase obrera, la discriminación de las mujeres o el caciquismo, destacaban la falta de conexión con la actualidad, ya que eran cosas que "havien passat i es quedaven en el passat" ["habían pasado y se quedaban en el pasado"] (E22). Pese a esto, no podemos dejar de destacar las 84 referencias a procesos históricos, la mayoría de ellas vinculada a la historia contemporánea y conectada con debates y problemáticas fácilmente relacionables con el presente.

Las finalidades de la asignatura de Historia de España

Tras indagar sobre la metodología y los contenidos, procedimos a preguntar acerca de los objetivos o finalidades de la asignatura de Historia de España, ya que esa información nos debía servir para perfilar el tipo de representación que tenían los entrevistados de esta disciplina escolar.

Como podemos ver en la Gráfica VI, la finalidad más citada era la que hacía referencia a un uso identitario de la enseñanza de la historia. Quince personas, así, destacaban su utilidad para el conocimiento de las "raíces" o de "nuestro pasado". Aunque nadie hablaba explícitamente de una historia nacionalizadora, la existencia de un relato nacional(ista) en el recuerdo de muchas de aquellas clases era más que evidente, un relato que, como sucedía desde el siglo XIX, solía buscar los orígenes nacionales en épocas muy lejanas y que presentaba la existencia de una identidad española, más o menos cambiante, al margen de épocas y contextos.

La segunda gran finalidad planteada en las entrevistas (en 14 de 40) hacía referencia a la adquisición de una "cultura general" sobre la Historia de España. Eso generalmente se traducía en una visión del conocimiento histórico (y de la cultura) bastante erudita, 


\section{GrÁFICA VI}

Finalidades socio-educativas de la asignatura de Historia de España

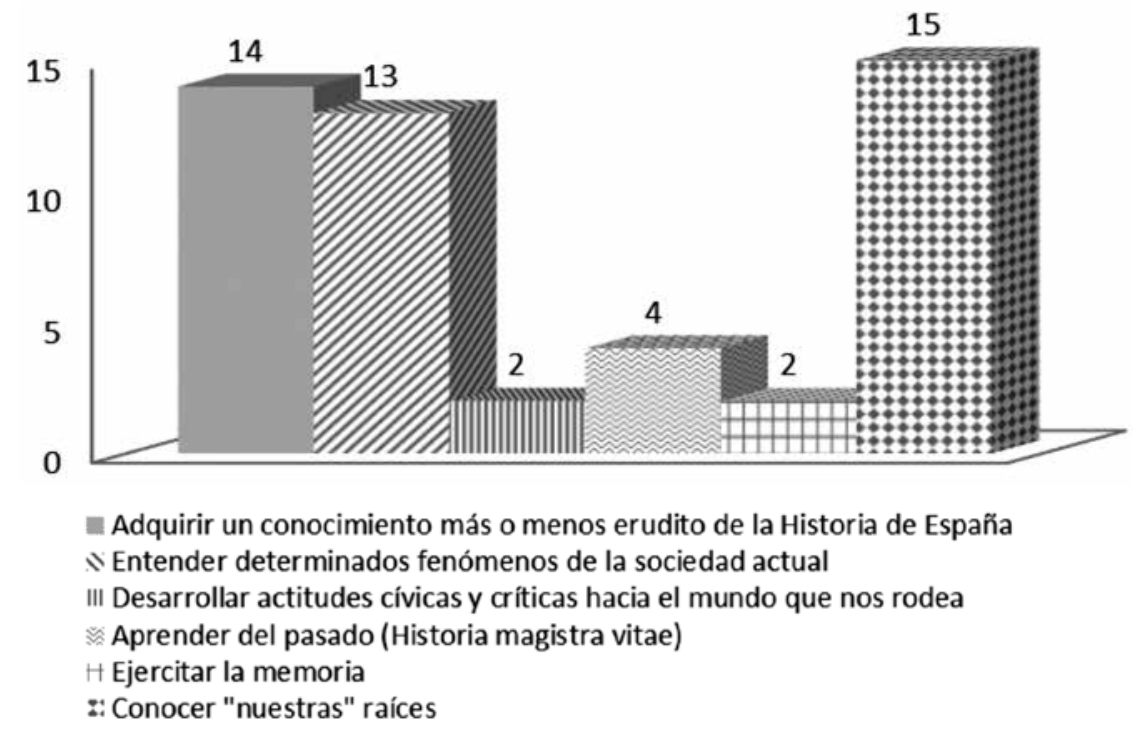

Fuente: Elaboración propia a partir de las entrevistas realizadas

anquilosada en el pasado y útil, como mucho, para "juegos de mesa" o para hacer turismo. Muchos consideraban que la historia no les había servido para nada, ya que no eran capaces de establecer conexiones con su vida o con lo que pasaba a su alrededor.

Prácticamente el mismo número de personas (13), en cambio, sí hablaba del conocimiento de la Historia de España para entender determinados fenómenos de la sociedad actual, objetivo que a menudo se relacionaba con la cuarta finalidad citada: aprender del pasado para no cometer errores en el presente. La Historia, pues, se erigía una vez más como una magistra vitae encargada de dar modelos de conducta y lecciones para el futuro:

E2: "Me suena incluso que había un epígrafe al comienzo del libro que decía 'aprender de los errores del pasado para no cometerlos en el futuro"”.

E16: "Creo que servía para buscar modelos de cosas que se hicieran bien (de gobernar, de vivir). Coger cosas buenas del pasado para acoplarlas a la vida de ahora".

E33: "Supongo que la finalidad es conocer nuestra historia para aprender cómo se habían hecho las cosas hasta ese momento y de ahí que cada uno sacara con- 
clusiones de lo que se hizo bien o mal. Y, sobre todo, no repetir en el futuro algunas de las partes de esa historia".

Sólo dos de las personas entrevistadas relacionaban la asignatura con el desarrollo de una ciudadanía crítica y comprometida. Para ellos, la Historia, entre otras cosas, les había dotado de instrumentos para valorar el presente y conocer unos derechos que, conseguidos con esfuerzo, había que defender:

E21: "Sirve para poder defender tus derechos, saber por qué estamos así, por qué no hemos estado antes así, para saber de dónde vienes y poder pelear por nuevos derechos, etc. Y ella fomentaba eso, que la gente tuviera cierta cultura para que, luego, pudiera tener ideas propias".

El principal problema, no obstante, no era que sólo fueran dos las entrevistas en las que se hablaba de una finalidad cívica, sino que, como veremos a continuación, la mayor parte de los entrevistados presentaba una concepción de la Historia que dificultaba un uso público de la misma desde una óptica crítica y transformadora.

\section{La concepción de la Historia escolar, ¿un obstáculo para una didáctica crítica?}

La idea de una didáctica de la historia crítica que dote al alumnado de herramientas analíticas para cuestio- nar el mundo que lo rodea y no reproducirlo inconscientemente no afloró, como hemos visto, cuando se preguntaba por las finalidades de la enseñanza de la Historia. Sin embargo, sí apareció, aunque de un modo diferente, cada vez que, durante la entrevista, se introducía el tema de la presencia de la política o el tratamiento de temas conflictivos en las clases de Historia de España. El 72,5\% de los entrevistados afirmaba que no recordaba que el profesorado hubiera utilizado la asignatura de un modo ideológico, razón por la que consideraba que las clases eran "objetivas". Esto permitía indagar sobre qué concepción tenían de la objetividad, cuestión que nos introducía en una representación de la historia muy tradicional, ya que una historia "objetiva" era, para muchos de estos ex alumnos de BUP, una historia factual. De esta manera, como ya plantearan los historicistas y los positivistas en el siglo XIX, la historia debía limitarse a contar los hechos "tal y como habían sucedido", sin valoraciones ni subjetividades, como si la propia selección de los hechos o de los procesos tratados no fuese ya un elemento subjetivo.

E3: "La historia es la que ha sido y, de hecho, si ya metes tus ideas políticas, aparte de que ya puedes chocar entre unas épocas y otras, creo que estás faltando a la verdad histórica".

E11: "El profesor de historia no debe posicionarse. La historia es la que es, y punto. Los hechos están ahí. 
No puedes tomar partido ni por unos ni por otros. [¿En ningún caso debe posicionarse?] Yo creo que no. Cada uno tendrá sus ideas, pero ellos te enseñan los hechos, y los hechos son los hechos. Tienes que ser objetivo".

E22: "Anar al fet, explicar-lo de la manera més senzilla. Simplement explicar el que va passar, sense donar adjectius positius o negatius a cap actor d'eixe moment" ["Ir al hecho, explicarlo de la manera más sencilla. Simplemente explicar lo que ocurrió, sin dar adjetivos positivos o negativos a ningún actor de ese momento"]

E26: "No recuerdo que las clases de Historia estuvieran ideologizadas. Tal como yo lo recuerdo, se trataba más bien de una exposición de acontecimientos históricos".

E28: "El profesor no debe posicionarse, debe transmitir la historia tal y como está escrita, sin dar su opinión personal".

En esta misma línea, era habitual encontrar referencias muy próximas al empirismo ingenuo que ya caracterizó a muchos positivistas decimonónicos que concebían el documento histórico como una especie de "túnel del tiempo" que permitía acceder al pasado, ignorando que las fuentes también son construcciones culturales que hay que someter a una profunda crítica ideológica y discursiva, más allá de la crítica de autenticidad:
E5: "Sería cuestión de intentar ser lo más neutro posible [...] Presentar los hechos (todos) y utilizar los materiales directamente (cartas magnas, leyes, etc.)".

La Historia, en estos casos, no era vista como un discurso sobre el pasado, sino como el propio pasado. Esto daba lugar a una concepción del conocimiento histórico que llevaba a muchos de los entrevistados a considerar que, para llegar a ese pasado, bastaba con aproximarse a unas fuentes que permitían reconstruir la sucesión de "hechos objetivos" (lo que "realmente sucedió"), como si fuera posible abarcar la totalidad de los acontecimientos del pasado o dar lugar a un relato desprovisto de interpretaciones (Jenkins, 2009).

Muchos de los que reclamaban el "no posicionamiento" del docente veían el recurso al libro de texto o el simple cumplimiento del currículum establecido como una prueba de objetividad, como si éstos estuviesen al margen de tendencias y de enfoques historiográficos e ideológicos (Apple, 1987; Kemmis, 1993; Torres, 1991; Bernstein, 1993). El docente, por tanto, era concebido como una especie de técnico que debía limitarse a "impartir" aquello que, por ley, venía establecido. Otros criticaban la introducción de elementos políticos en clase y señalaban que el posicionamiento ideológico del profesor suponía una interferencia en el pensamiento de un alumnado influenciable y en formación, ignorando que los estudiantes, como cualquier persona, reciben permanen- 
temente influencias político-ideológicas procedentes de ámbitos muy diversos (Freire, 1993).

Esta visión de una "historia objetiva", tan extendida entre los entrevistados, no sólo dificulta considerablemente la implementación de una didáctica crítica, sino que puede conllevar peligrosos relativismos amparados por una teórica "neutralidad" del conocimiento:

E4: "La història l'has de contar objectivament. Contar en cada cas allò que va passar, però sense ficar a uns com a dolents $i$ a altres com a bons" ["La historia debes contarla objetivamente. Contar en cada caso lo que sucedió, pero sin poner a unos como malos y a otros como buenos"].

E21: "Yo creo que el profesor no debe posicionarse en ningún momento porque cada uno ha de sacar sus propias conclusiones sobre los hechos. Has de explicar los hechos lo mejor que puedas para que, luego, cada uno tenga su idea y se vaya formando su propia ideología y su propia conciencia. $\mathrm{Ni}$ siquiera en el caso del nazismo creo que deba posicionarse".

En estos casos, resulta interesante ver cómo algunos de los entrevistados no admitían el posicionamiento cuando se hablaba de hechos próximos (en el espacio o en el tiempo), pero no tenían grandes inconvenientes cuando se trataba de acontecimientos lejanos o cuando la opinión encajaba con lo que ellos consideraban "un sentir mayoritario". En todo caso, la política/ideología, en un sentido más o menos negativo, entraba en escena cuando se hablaba del presente, de lo que se desprendía a menudo una concepción de la Historia aislada y sin implicaciones para la actualidad.

E3: "Si es contemporáneo lo veo más peliagudo que que des tu opinión sobre Felipe V. Yo qué sé. Eso puede ser hasta anecdótico: 'este personaje era tal o cual', pero los contemporáneos es más peliagudo, pienso yo".

E22: "Depén del que estigues donant. Si estàs veient la Guerra Civil no t'has de posicionar, però tampoc pots dir que uns van ser els salvadors d'Espanya i els altres rö̈ns. Però si estudies la Segona Guerra Mundial, el que van fer els nazis va estar molt mal i això sí que s'ha de dir. Sinó correm el risc de... això és neutre, això va passar, a algú se li pot creuar els cables $i$ repetir-ho [I un episodi així, no el podem trobar dins de la història d'Espanya?] És complicat, perquè tot toca molt de prop. Si queda prop és millor no posicionar-se perquè encara hi ha gent que pot sentir-se afectada". ["Depende de lo que estés dando. Si están viendo la Guerra Civil no te debes posicionar, pero tampoco puedes decir que unos fueron los salvadores de España y los otros los malos. Pero si estudias la Segunda Guerra Mundial, lo que hicieron los nazis estuvo 
muy mal y eso sí que se debe decir. Si no, corremos el riesgo de... eso es neutro, eso pasó, a alguien se le pueden cruzar los cables y repetirlo [...] Es complicado, porque te toca muy de cerca. Si queda cerca es mejor no posicionarse porque aún hay gente que puede sentirse afectada"].

E4: "[Penses, per tant, que el professor mai no s'hauria de posicionar?] Home, coses tan clares com l'ús de la tortura, que va en contra dels drets de les persones, potser aqui sí que et podries posicionar un poc i comentar-ho com a una cosa roïna, perquè això és una cosa que no està bé $i$ atenta contra els drets de cada persona, però més enllà, no" ["Hombre, cosas tan claras como el uso de la tortura, que va en contra de los derechos de las personas, quizás aquí sí que te podrías posicionar un poco y comentarlo como algo malo, porque eso es algo que no está bien y atenta contra los derechos de cada persona, pero más allá, no”].

La conexión entre los ejemplos y argumentos presentados por los entrevistados y algunos de los debates que, en los últimos años, han tenido una presencia notable en el ámbito público a través, sobre todo, de los medios de comunicación de masas ("Guerra de las Humanidades", Ley de Memoria Histórica, Educación para la Ciudadanía, etc.) es más que evidente. Estos debates han servido para resituar y revalorar el papel de la memoria en el proceso de construcción del conocimiento histórico; sin embargo, en muchas ocasiones, han sido utilizados también para fomentar comportamientos antimemorialísticos basados en el rechazo de una nueva Historia más comprometida y en la reivindicación de la Historia "de siempre" en aras de la supuesta neutralidad del conocimiento, de la armonía social ("no reabrir heridas") o, incluso, del respeto a la tradición (como si ésta fuera natural e inmutable).

\section{Conclusiones}

Con una concepción de la Historia como la que hemos presentado en estas páginas es muy difícil desarrollar lo que actualmente denominamos competencia social y ciudadana. A finales de los años ochenta y principios de los noventa, en un momento de eclosión y auge de los grupos de innovación, fueron muchos los profesores de Geografía e Historia que intentaron cambiar las cosas. No obstante, como confirman algunos de los testimonios analizados, tuvieron que enfrentarse, entre otros, a un gran obstáculo: la concepción que tenía su alumnado, y una parte importante de sus colegas, de la Historia y de la Geografía que se debía enseñar en escuelas e institutos (sobre obstáculos similares en Geografía, véase Fernández Caso, Gurevich, Souto, Bachmann, Ajón, y Quintero, 2010).

Hoy, más de dos décadas después, todo apunta a que las resistencias y las dificultades para la innovación docen- 
te no sólo no se han reducido, sino que han ido ganando fuerza con el auge de posturas neopositivistas que, en aras de la objetividad, excluyen el conflicto y reivindican el retorno a una historia tradicional.

El aula, como señalan numerosos especialistas en Didáctica de las Ciencias Sociales (Pagès, 2005; Valls, 2009; López Facal, 2011), se debe presentar como un espacio privilegiado para la confrontación de informaciones, el análisis reflexivo y el desarrollo de un pensamiento más crítico y abierto. Esto sólo es posible si no se renuncia a trabajar polémicas y controversias en clase, lo que obliga a ir más allá del simple relato de hechos y personajes y a introducir posicionamientos que no siempre serán del gusto de todos, pero que son necesarios para estimular el debate en la esfera pública democrática (Giroux, 2001).

Consideramos que la tendencia de buena parte de las personas entrevistadas a huir de las implicaciones ciudadanas y políticas y la reivindicación de una historia factual, desprovista de valores explícitos y de contenidos que puedan suscitar conflictos, evidencia con claridad cuál es la representación social de la Historia más extendida entre la muestra: una representación enmarcada dentro de una idea según la cual la escuela debe ser "neutra" para ser respetuosa. En los casos estudiados, hemos podido comprobar que ello suele conducir a una educación poco reflexiva y pobre desde una perspectiva ciudadana y a una historia completamente desproblematizada y poco útil para el pre- sente. Además, no podemos olvidar que los intentos de despolitizar el lenguaje de la escuela a menudo tienden a reproducir y legitimar discursos dominantes que acaban erigiéndose como "naturales" y "verdaderos" (Giroux, 1990).

Una Historia crítica debe ajustar cuentas con el pasado y, si es necesario, dar lugar a una contramemoria encargada de resaltar las discontinuidades, las contradicciones y los cambios para desplazar aquello que, con tanto acierto, Nietzsche denominó historia monumental e historia anticuaria (Cuesta, Mainer, Mateos, 2008; Samuel, 2008). Para conseguirlo, es necesario que los docentes, como apunta Giroux, se vean y actúen como intelectuales transformadores, ya que sólo así darán lugar a una historia abierta, liberadora, útil para el presente y para la formación crítica de personas autónomas. Como señala Paulo Freire en la obra con la que iniciábamos este artículo, el problema no es tanto que la enseñanza sea directiva (siempre lo es) como que interfiera de un modo restrictivo en la capacidad creadora, formuladora e indagadora de los estudiantes. No se debe confundir, por tanto, la politicidad y el posicionamiento de la educación con la manipulación, el adoctrinamiento o el autoritarismo (Freire, 1993).

Así pues, más allá de la innovación metodológica, de la incorporación de nuevos recursos o de la adopción de nuevos enfoques, resulta imprescindible la deconstrucción de esta representación tan reforzada por el peso de la tradición y, en la actualidad, tan legiti- 
mada por determinados sectores políticos o medios de comunicación de masas. En esta línea, queremos acabar con el testimonio de una antigua estudiante de BUP, y actual profesora de Historia, partidaria de un uso público, vivo, comprometido y honesto de su asignatura; un testimonio que confirma que el cambio, pese a todo, sigue siendo posible:

E13: "La història no és objectiva, per molt que vulguem. L'historiador no és objectiu i el professor d'història, com a subjecte que és, com a ciutadà, s'ha de posicionar. Tu no pots dir 'això és el feixisme, això és la democràcia, tria'; més que res perquè els teus alumnes també són persones en formació, no són persones que estiguen tan formades o que tinguen totes les eines al seu abast per poder triar moltes vegades. A ells també els has de guiar, els has de ficar exemples d'avui en dia: 'compareu, què us sembla com s'aproven les lleis actualment? Es fan pel parlament? Es fan per decret? Es referenden? Quina és la diferència?' Jo crec que sí, que el professor s'ha de posicionar" ["La historia no es objetiva, por mucho que queramos. El historiador no es objetivo y el profesor de historia, como sujeto que es, como ciudadano, debe posicionarse. Tú no puedes decir 'esto es el fascismo, esto es la democracia, elige'; sobre todo porque tus alumnos también son personas en formación, no son personas que estén tan formadas o que tengan todas las herramientas a su alcance para poder elegir muchas veces. A ellos también tienes que guiarlos, les debes poner ejemplos de hoy en día: 'comparad, ¿qué os parece cómo se aprueban las leyes actualmente? ¿Se hacen en el Parlamento? ¿Se hacen por decreto? ¿Se refrendan? ¿Cuál es la diferencia?' Yo creo que sí, que el profesor se debe posicionar"].

\section{Referencias bibliográficas}

APPLE, M. W. (1987), Educación y poder, Barcelona, Paidós.

BARTON, K. C. (2010), Investigación sobre las ideas de los estudiantes acerca de la Historia, Enseñanza de las Ciencias Sociales, ${ }^{\circ}$ 9, pp. 97-114. BERNSTEIN, B. (1993), La estructura del discurso pedagógico, Madrid, Morata-Paideia.

CARRERAS, J. J. (2000), Razón de Historia. Estudios de historiografía, Madrid, Marcial Pons.

CARRETERO, M.; ROSA, A., y GONZÁLEZ, M. F. (2006), Enseñar historia en tiempos de memoria. Introducción, en CARRETERO, M.; ROSA, A., y GONZÁLEZ, M. F. (comp.), Enseñanza de la historia y memoria colectiva, Buenos Aires. Paidós, pp. 13-38. CUESTA, R. (1997), Sociogénesis de una disciplina escolar: la Historia, Barcelona, Ediciones Pomares-Corredor. CUESTA, R.; MAINER, J., y MATEOS, J. (2008), La genealogía, historia del presente y didáctica crítica, en MAINER, J. (coord.), Pensar críticamente 
la educación escolar. Perspectivas y controversias historiográficas, Zaragoza, Publicaciones de la Universidad de Zaragoza, pp. 51-82.

ESCOLANO, A. (2011), La escuela en la memoria, en LOMAS, C. (coord.), Lecciones contra el olvido. Memoria de la educación y educación de la memoria, Barcelona, Octaedro, pp. 61-76.

FERNÁNDEZ CASO, M. V.; GUREVICH, R.; SOUTO, P.; BACHMANN, L.; AJÓN, A., y QUINTERO, S. (2010), La imagen pública de la Geografía. Una indagación desde las visiones de profesores y padres de alumnos secundarios, Biblio $3 W$. Revista Bibliográfica de Geografía y Ciencias Sociales, vol. XV, $\mathrm{n}^{\circ} 859$, http://www.ub.edu/geocrit/b3w-859. htm

FREIRE, P. (1993), Pedagogía de la esperanza, Madrid, Siglo XXI.

FUENTES MORENO, C. (2004), Concepciones de los alumnos sobre la Historia, Enseñanza de las Ciencias Sociales, $\mathrm{n}^{\circ} 3$, pp. 75-83.

GIROUX, H. A. (1990), Los profesores como intelectuales. Hacia una pedagogía crítica del aprendizaje, Barcelona, Paidós/MEC.

GIROUX, H. A. (2001), Cultura, politica y práctica educativa, Barcelona, Graó.

IGGERS, G. G. (1998), La ciencia histórica en el siglo $X X$, Barcelona, Idea Universitaria.

JENKINS, K. (2009), Repensar la historia, Madrid, Siglo XXI.
KEMMIS, S. (1993), El currículum: más allá de la teoría de la reproducción, Madrid, Morata.

LOMAS, C. (coord.) (2011), Lecciones contra el olvido. Memoria de la educación y educación de la memoria, Barcelona, Octaedro.

LÓPEZ FACAL, R. (2011), Aprender de los conflictos, Íber. Didáctica de las Ciencias Sociales, Geografía e Historia, $\mathrm{n}^{\circ} 69$, pp. 5-7.

LOWENTHAL, D. (1998), El pasado es un lugar extraño, Madrid, Akal.

MAESTRO, P.(2005), La idea de España en la historiografía escolar del siglo XIX, en MORALES, A. y ESTEBAN, M. (eds.), ¿Alma de España? Castilla en las interpretaciones del pasado español, Madrid, Marcial Pons, pp. 141-194.

MARTÍNEZ VALCÁRCEL, N.; SOUTO GONZÁLEZ, X. M., y BELTRÁN LLAVADOR, J. (2006), Los profesores de Historia y la enseñanza de la Historia en España. Una investigación a partir de los recuerdos de los alumnos, Enseñanza de las Ciencias Sociales, no 5, pp. 55-71.

MORANT, I. (1996), Mujeres e historia o sobre las formas de la escritura y de la enseñanza de la historia, Didáctica de las Ciencias Experimentales y Sociales, $\mathrm{n}^{\circ} 10$, pp. 11-34.

MORENO, A. (1986), El arquetipo viril, protagonista de la historia. Ejercicios de lectura no androcéntrica, Barcelona, La Sal.

PAGÈS, J. (2005), Educación cívica, formación política y enseñanza de las ciencias sociales, de la geografía y 
de la historia, Íber. Didáctica de las Ciencias Sociales, Geografía e Historia, $\mathrm{n}^{\circ} 44$, pp. 45-56.

PARRA MONSERRAT, D. (2012), Aprender la patria. El relato nacionalista en la enseñanza de la geografía y la historia de España, Scripta Nova. Revista Electrónica de Geografía y Ciencias Sociales, vol. XVI, $\mathrm{n}^{\mathrm{o}} 418$ (33), http://www.ub.es/geocrit/ sn/sn-418/sn-418-33.htm

SAMUEL, R. (2008), Teatros de la memoria, Valencia, Publicacions de la Universitat de València.

SCOTT, J. W. (2008), Género e historia, México, Fondo de Cultura Económica. SOUTO, X. M. (2008), Una educación geográfica para el siglo XXI: aprender competencias para ser ciudadano en el mundo global, Diez años de cambios en el Mundo, en la Geografía y en las Ciencias Sociales, 19992008. Actas del X Coloquio Internacional de Geocrítica, Barcelona, Universidad de Barcelona, http://www. ub.es/geocrit/-xcol/19.htm

TORRES, J. (1991), El currículum oculto, Madrid, Morata.

VALLS, R. (1991), La exaltación patriótica como finalidad fundamental de la historia en la educación obligatoria: una aproximación histórica, Didáctica de las Ciencias Experimentales y Sociales, $\mathrm{n}^{\circ} 5$, pp. 33-47.

VALLS, R. (2009), Historia y memoria escolar. Segunda República, Guerra Civil y dictadura franquista en las aulas, Valencia, Publicacions de la Universitat de València. 
